\title{
DINAMIKA KOMUNIKASI KONTRAKTOR - PUBLIK: KAJIAN FENOMENOLOGI KOMUNIKASI DALAM PELAKSANAAN PROYEK INFRASTRUKTUR DI SUMATERA BARAT
}

\author{
Emeraldy Chatra1; Ilham Havifi2; Diego3
}

1) Jurusan Ilmu Komunikasi FISIP Universitas Andalas; emeraldy1962@gmail.com

2) Jurusan Ilmu Komunikasi FISIP Universitas Andalas; ilhamhavifi@ gmail.com

3) Jurusan Ilmu Komunikasi FISIP Universitas Andalas; dyandreas@gmail.com

\begin{abstract}
ABSTRAK
Komunikasi seharusnya dapat mengurangi resiko kegagalan proyek infrastruktur karena dengan komunikasi orang dapat mencapai commonness - kesamaan pandangan yang selanjutnya bertransformasi kepada kerjasama yang baik. Oleh sebab itu komunikasi memegang peranan yang sangat penting dalam upaya mencapai sukses pengerjaan proyek infrastruktur. Di Sumatera Barat tidak sedikit proyek infrastruktur berbiaya mahal berakhir dengan kegagalan.komunikasi memegang peranan penting alam proyek infrastruktur kajian-kajian akademik yang dilakukan secara serius oleh pembelajar ilmu komunikasi terkait isu tersebut justru sangat minim. Untuk mengatasi kelangkaan tersebut, maka penelitian ini direncanakan akan mempelajari secara detil proses, karakteristik, power relations dan penyebab gagalnya proyek infrastruktur dari perspektif ilmu komunikasi, lebih khusus lagi Public Relations. Analisis penelitian ini dimulai dengan memetakan persoalan-persoalan yang dihadapi dalam pelaksanaan proyek infrastruktur yang dilaksanakan oleh Pemerintah Khususnya pada riset ini Pemerintah Provinsi Sumatera Barat, menarasikan pentingnya bagi masyarakat dengan menggali pengalamannya dan menganalisis domain-domain yang dianggap potensial untuk mengkaji fenomena komunikasi yang terjadi dalam pelaksanaan proyek infrastruktur.
\end{abstract}

Kata Kunci: Public Relations, Proyek Infrastruktur, Kontraktor, Publik

\begin{abstract}
Communication that can reduce the risk of infrastructure projects because with communication people can achieve common ground - supporting views that are then transformed for good cooperation. Therefore, communication plays a very important role in achieving success in infrastructure project work. In West Sumatra there are no expensive infrastructure projects that end in problems. Communication plays an important role in academic-study infrastructure projects carried out in full by communication science learners on this issue. To overcome this scarcity, this study will discuss the processes, characteristics, power relations and causes of the failure of infrastructure projects from the perspective of communication science, more specifically Public Relations. The analysis of this research begins by mapping out discussions discussing the implementation of projects carried out by the Government, especially in this research in the Government of West Sumatra Province, narrating the interests of the community by exploring their experience and analyzing domains that have the potential to study communication phenomena that occur in infrastructure project implementation.
\end{abstract}

Keywords: Public Relations, Infrastructure Projects, Contractors, Public 


\section{NIRK \\ 1.INTRODUCTION}

E-ISSN : 2656-4718

P-ISSN : 2302-8106

Jurnal Ranah Komunikasi (JRK)

Volume 3 Nomor 2 Tahun 2019

Komunikasi seharusnya dapat mengurangi resiko kegagalan proyek infrastruktur karena dengan komunikasi orang dapat mencapai commonness - kesamaan pandangan yang selanjutnya bertransformasi kepada kerjasama yang baik (Comfort, 2007 Husain, 20131 du escu et al, 2015). Oleh sebab itu komunikasi memegang peranan yang sangat penting dalam upaya mencapai sukses pengerjaan proyek infrastruktur.

Di Sumatera Barat tidak sedikit proyek infrastruktur berbiaya mahal berakhir dengan kegagalan. Di sebelah kantor walikota Padang, Aia Pacah masih dapat dilihat „puing-puing kegagalan proyek ${ }^{\text {ee }}$ yang pernah dibuat pemerintah Kota Padang. Puing-puing itu berupa bangunan tak terpakai. Letaknya persis di sebelah kantor walikota Padang yang baru. Sejak dibangun memang tidak pernah digunakan. Bangunan itu bagian dari Terminal Regional Bingkuang (TRB) yang dibangun pada tahun 1999 dengan biaya miliaran rupiah.

Chatra (2017) menulis di harian Padang Ekspres, nasib TRB sama dengan Pasar Amur, Nagari Batagak, Kabupaten Agam. Pasar yang berdiri megah di sisi jalur padat Padang - Bukittinggi itu tidak pernah berfungsi sebagai pasar konveksi sejak diresmikan Menteri Koperasi dan PKM RI Ali Marwan Hanan pada tanggal 11 Agustus 2002. Dua proyek gagal itu hanya sebagian dari sekian banyak proyek gagal di Sumbar, yang sangat menyolok mata, bergelanggang mata orang banyak. Sebenarnya masih banyak lagi. Awal 2017 media memberitakan adanya enam proyek gagal di Sumbar yaitu pembangunan jalan Duku Sicincin $(67,74 \%)$, peningkatan jalan Palupuh-Pua Gadih-Koto Tinggi (67,08\%), jalan Lubuk Sikaping-Talu (88,25\%), Jembatan Lolong (75\%), Jembatan Malampah (51,53\%) dan Jembatan Padang Tarok $(80,60 \%)$.

Di tingkat nasional faktor komunikasi juga menjadi salah satu masalah yang sangat terkait dengan kualitas infrastruktur. Awal 2019 Bank Dunia mengeluarkan pernyataan bahwa kualitas infrastruktur Indonesia berkualitas rendah. Reporter CNN (2019) melaporkan bahwa Bank Dunia berpendapat, pemerintah dan pemangku kepentingan tidak memiliki koordinasi yang baik (dalam pembangunan infrastruktur - pen.), sehingga menciptakan kebingungan bagi investor. "Mereka tidak yakin harus berkomunikasi dengan siapa dan pihak yang akan memastikan komitmen pemerintah dalam memobilisasi dana proyek infrastruktur".

Meskipun sangat disadari bahwa komunikasi memegang peranan penting alam proyek infrastruktur kajian-kajian akademik yang dilakukan secara serius oleh pembelajar ilmu 
komunikasi terkait isu tersebut justru sangat minim. Untuk mengatasi kelangkaan teran tersebut, maka penelitian ini direncanakan akan mempelajari secara detil proses, karakteristik, power relations dan penyebab gagalnya proyek infrastruktur dari perspektif ilmu komunikasi, lebih khusus lagi Public Relations.

Public relations pada riset ini memiliki tugas untuk mengelola domain besar, yaitu komunikasi kontraktor dengan publiknya yaitu masyarakat. Dalam domain ini beberapa segmen praksis sangat penting keteribatannya seperti government relations, media relations, community relations, government affairs, Industrial Relations, Employee/Member Relations yang menekankan bahwa komunikasi memegang peranan yang sangat penting dalam upaya mencapai sukses pengerjaan proyek infrastruktur.

Pemerintah juga memiliki keterlibatan penting sebagai pihak yang sangat terlibat dalampelaksanaan proyek-proyek infrastruktur ini, baik komunikasi yang dilakukan pemerintah dengan kontraktor maupun masyakarakat yang terlibat disekitar lingkungan proyek infrastruktur terkaiy.Berhubungan dengan penelitian ini telah dilakukan oleh Chatra (2017), Ehling (1984, 1985), Lauzen (1986), dan Murphy (1991). Chatra (2017) mengembangkan teori PR berdasarkan teori keputusan, teori permainan dan teori resolusi konflik. Lauzen membangun teorinya berdasarkan empat model tersebut.

Analisis penelitian ini dimulai dengan memetakan persoalan-persoalan yang dihadapi dalam pelaksanaan proyek infrastruktur yang dilaksanakan oleh Pemerintah Khususnya pada riset ini Pemerintah Provinsi Sumatera Barat, menarasikan pentingnya bagi masyarakat dengan menggali pengalamannya dan menganalisis domain-domain yang dianggap potensial untuk mengkaji fenomena komunikasi yang terjadi dalam pelaksanaan proyek infrastruktur.

Adapun tujuan dari penelitian ini adalah Menggali pengalaman kontraktor dalam berhubungan dengan publik eksternal dan internalnya, Membuat peta masalah komunikasi yang dihadapi kontraktor melalui reduksi eidetik, Melakukan reduksi transendental untuk mendapatkan esensi masalah komunikasi yang dihadapi kontraktor, dan Membangun dan mengembangkan konsep Public Relations Infrastruktur

\section{METHODOLOGY OF RESEARCH}

Penelitian ini menggunakan metode kualitatif. Pengumpulan data primer dilakukan dengan wawancara mendalam dan observasi. Data sekunder diperoleh dari dokumen, khususnya berita-berita yang dipublikasikan oleh media-media online dan media cetak. 
Husserl yaitu:

1. Reduksi Epoche

Epoche berasal dari bahasa Yunani, yang berarti menahan diri untuk menilai. Dalam Epoche, menurut Moustakas (1994:33), penilaian, pemahaman dan pengetahuan sehari-hari dikesampingkan dahulu, dan fenomena dimunculkan dan direvisi secara segar, apa adanya, dan dalam pengertian yang terbuka.

2. Reduksi Eidetik

Pada reduksi ini yaitu menyaring fenomena sampai menemukan eidos-nya atau konsep/ intisari sampai kepada wesen-nya (hakikat). Karena itu reduksi juga disebut sebagai wesenchau artinya kita melihat hakikat sesuatu. Tujuan dari reduksi ini adalah untuk mengungkapkan struksur dasar (esensi, eidos, atau hakikat) dari fenomena (gejala) yang bersifat murni berdasarkan pengalaman informan.

3. Reduksi Transendental

Pada tahap ini tidak lagi membahas mengenai objek atau fenomena, tetapi reduksi ini berfokus ke subjek itu sendiri. Jadi reduksi transendental merupakan subjek yang dihayati oleh kesadaran itu sendiri. Kesadaran subjek yang menyampaikan pengalaman yang telah ditemukan eidosnya atau konsepnya, sehingga konsep-konsep yang ditemukan dikaitkan anatara satu dan lainnya yang akan menghasilkan makna, ideologi atau bentuk keyakinan (Daulay, 2010:53).

\section{RESULT AND DISCUSSION}

\section{Pengalaman kontraktor dalam berhubungan dengan publik eksternal dan internalnya}

Komunikasi adalah hal yang sangat penting dalam pelaksanaan proyek infrastruktur, karena itulah sangat penting dipahami berbagai proses yang terkait dengan komunikasi yang terjalin terutama antara pelasana proyek kontraktor dengan publiknya. Dalam pelaksanaannya yang terpenting demi lancarnya suatu pekerjaan selain sumber daya manusia yaitu komunikasi antara pihak- pihak yang terlibat dalam proyek konstruksi antara lain kontraktor dengan publiknhya. Tanpa adanya komunikasi yang baik antara kontraktor dengan publiknya dengan baik maka proyek pembangunan infrastruktur tersebut tidak akan berjalan sesuai dengan rencana. Komunikasi adalah hal yang sangat penting dalam pengelolaan proyek. Ancaman terbesar yang mengakibatkan proyek tidak berhasil adalah kegagalan membangun kepercayaan dengan publiknya baik itu public internal maupun public eksternalnya.

Untuk melaksanakan pembangunan di lapangan, tentu saja membutuhkan komunikasi yang baik dari seorang kontraktor yang dapat melaksanakan pekerjaan dari seorang owner agar pekerjaan tersebut dapat dilaksanakan sesuai dengan yang direncanakan. Kontraktor adalah orang atau badan yg menerima pekerjaan dan menyelenggarakan pelaksanaan 
pekerjaan sesuai biaya yg telah ditetapkan berdasarkan gambar rencana dan peraturan serta syarat - syarat yang telah ditetapkan. Hak dan kewajiban dari seorang kontrakor adalah melaksanakan pekerjaan sesuai dengan gambar rencana, membuat gambar pelaksanaan yang disahkan oleh konsultan pengawas, menyediakan alat keselamatan kerja, membuat laporan hasil perkerjaan, serta menyerahkan seluruh atau sebagian pekerjaan yang telah di selesaikan.

Komunikasi antara kontraktor dan publik ini dilaksanakan untuk mengatasi kesulitan yang muncul di lapangan agar dapat mencapai keberhasilan proyek pembangunan infrastruktur. Untuk mencapai keberhasilan tersebut diperlukan komunikasi yang efektif antara kontraktor dengan publiknya. Oleh karena itulah perlu dilakukan penelitian untuk menganalisis indicator dari dinamika komunikasi yang efektif untuk menunjang keberhasilan kontraktor dalam menyelesaikan pekerjaan proyek dengan publiknya di lingkungan sekitar pembanbgunan. Penelitian ini diawali dengan melakukan kajian fenomenologi untuk mendapatkan pengalaman kontraktor terkait komunikasi yang dilakukan dengan public demi memastikan kelancaran keberhasilan proyek pembangunan infrasturktur di Sumatera Barat, dimana konsen proyek pembangunan pada penelitian ini terfokus di Kota Padang sebagai Ibu Kota Provinsi Sumatera Barat.

Dinamika komunikasi memberikan pengaruh yang positif dan signifikan terhadap keberhasilan pembangunan infrastruktur. Dinamika komunikasi kontraktor dalam proses penyampaian pesan efektif untuk memberitahu atau untuk mengubah sikap, pendapat atau perilaku baik langsung secara lisan maupun tidak langsung kepada publiknya. Upaya komunikasi dilakukan kontraktor sebagai usaha untuk membangun kebersamaan pikiran tentang suatu makna atau pesan yang dianut secara bersama untuk sebagai indikator penting pada komunikasi yang efektif, yakni frekuensi komunikasi, komunikasi dua arah, kejelasan isi pesan, kejujuran berkomunikasi, dan resolusi konflik.

Dinamika komunikasi dalam meningkatkan kesuksesan komunikasi yang terjalin dalam pelaksanaan pembangunan infrastruktur inilah hal penting untuk memastikan jalannya pembangunan dengan baik disamping menunjang prasarana pembangunan. Aspek prasarana ini seperti kehidupan sosial maupun ekonomi mempunyai prasarana sendiri, yang merupakan satuan terbesar dan alat utama dalam berbagai kegiatan. Oleh karena itu, dalam mengsukseskan pembangunan setiap lembaga sosial dan sektor kehidupan ekonomi harus memperhatikan infrastrukturnya. Berdasarkan pengalaman yang ada pembangunan sering terjadi tidak efisien dan efektif karena tidak sesuai dengan aspirasi daerah, tidak sesuai 
dengan potensi daerah dan permasalahan daerah, serta penyimpang an bersifat teknis maupun non-teknis yang tentu saja menimbulkan berbagai dampak sosial yang tidak sedikit.

\section{Komunikasi Kontraktor dengan Publik Internal}

Dalam menjalin komunikasi dengan publiknya, kontraktor memiliki peran memberikan perencanaan, pengarahan, dan rekomendasinya dalam menentukan arah serta kebijaksanaan pelaksanaan proyek. Kontraktor juga berfungsi sebagai konsultan dalam suatu badan multi disiplin profesional, tangguh, dan independen yang bekerja untuk pemilik proyek dari awal perencanaan sampai pengoperasian proyek, mampu bekerjasama dengan arsitek guna mencapai hasil yang optimal dalam aspek waktu, biaya, serta kualitas seperti yang sudah ditetapkan sebelumnya.

Kontraktor di Sumatera Barat dibawahi asosiasi Gabungan Perusahaan Kontruksi Nasional Indonesia (GAPEKSINDO). Seiring dengan perkembangan jasa konstruksi di tanah air Indonesia ini serta amanat Undang-Undang No. 18 Tahun 1999 tentang Jasa Konstruksi yang menyatakan bahwa Perusahaan Jasa Konstruksi sebagai bagian Masyarakat Jasa Konstruksi dan sekaligus sebagai bagian dari kesatuan masyarakat pelaku ekonomi Indonesia, maka sejak Tanggal 27 Juli 2002, Asosiasi GAPEKSINDO dideklarasikan di Makassar Sulawesi Selatan, dengan akta notaris Hidayat Aziek, SH Nomor 6 Tanggal 27 Juli 2002. GAPEKSINDO ini merupakan wadah organisasi perusahaan perusahaan yang bergerak dibidang jasa konstruksi yang dimana meliputi bidang arsitektural, bidang sipil, bidang mekanikal, bidang elektrikal, dan bidang tata lingkungan.

Pada awal tahun 2002 didirikan hingga tahun 2012 (berjalan), GAPEKSINDO telah melayani anggotanya 22.916 badan usaha yang bergerak dibidang jasa konstruksi yang tersebar pada 450 kantor daerah/cabang diseluruh propinsi di Indonesia, serta pada tanggal 4 November 2008 GAPEKSINDO telah mendapatkan sertifikasi manajemen mutu ISO 9001:2008 dari TUV Nord.

GAPEKSINDO pada tanggal 14 Juni 2011, GAPEKSINDO termasuk salah satu Asosiasi Perusahaan yang memenuhi persyaratan yang memenuhi kriteria untuk menjadi kelompok unsur lembaga tingkat nasional sesuai dengan Keputusan Menteri Pekerjaan Umum Nomor : 154/KPTS/M/2011. GAPEKSINDO memiliki visi terwujudnya oragnisasi yang mandiri dan profesional sebagai wadah berperannya pelakssana konstruksi dalam menjalankan pengabdian usahanya menuju pembangunan bangsa Indonesia yang bermartabat. Dengan misi menghimpun dan mengembangkan perusahaan nasional dibidang 
usaha pelaksana jasa konstruksi dalam tatanan dunia usaha yang sehat, mampu bersinergi sesama pelaksana jasa konstruksi.

Gabungan Perusahaan Konstruksi Nasional Indonesia (GAPEKSINDO) merupakan asosiasi yang beranggotakan perusahaan - perusahaan yang bergerak dalam jasa konstruksi. Pada awalnya DPD GAPEKSINDO Provinsi Sumatera Barat ini hingga tahun 2012 (berjalan) sekarang telah beranggotakan 1708 Badan Usaha yang telah dilayani di 19 Tingkat Kota/kab dipropinsi Sumatera Barat dari 7 Kota dan 12 Kabupaten yang ada.

\section{Esensi masalah komunikasi yang dihadapi kontraktor melalui reduksi transendental}

Kemampuan kontraktor dalam berkomunikasi secara efektif sangat menentukan keberhasilan proyek infrastruktur tersebut. Komunikasi dan informasi yang salah mengakibatkan kinerja yang kurang baik diantaranya : pembengkakan biaya proyek, buruknya mutu pekerjaan dan terjadinya keterlambatan waktu pengerjaan dari jadwal semestinya. Proyek konstruksi pada umumnya, karakteristik proyek sangat mempengaruhi lingkungan sekitar. Terdapat beberapa faktor-faktor yang dapat mempengaruhi karakteristik proyek, antara lain : Keterbatasan lokasi dan lahan, resiko politik, resiko ekonomi, dampak pada publik, persetujuan teknis oleh otoritas, dan tersedia dana yang cukup.

\section{Public Relations Infrastruktur sebagai sebuah solusi permasalahan komunikasi dalam proyek infrastruktur.}

Semakin berjalan-nya waktu definisi humas pada saat ini berbeda-beda, penggunaan istilah humas yang semakin luas semakin mengaburkan arti yang sebenarnya. Definisi humas dapat diartikan berbeda sesuai dengan fungsinya. Moore mendefinisikan humas sebagai “ Hubungan dengan masyarakat luas, seperti melalui publisitas khususnya fungsi-fungsi korperasi, organisasi dan sebagainya yang berhubungan dengan usaha untuk menciptakan opini publik dan citra yang menyenangkan untuk dirinya sendiri” (Moore, 2004:6).

Proses membina kebijaksanaan umum, menjamin pelaksanaan berbagai kebijaksanaan dan komunikasi mengenai kebijaksanaan kepada khalayak sehingga menghasilkan pertukaran gagasan formal secara dua arah antara sebuah organisasi dengan khalayaknya merupakan pencerminan dari fungsi hubungan masyarakat. Penciptaan opini publik yang menyenangkan merupakan tujuan utama humas. Disamping fungsi dan perananya, humas harus dapat menjalankan tugastugasnya demi tercapainya tujuan yang semata-mata untuk mendukung keberhasilan organisasi diantaranya adalah persiapan artikel pemberitaan, siaran pers, foto 
dan latar belakang informasi bagi para penulis dan redaktur aktume xx Nomor xx Tahyn 20xx 2004 : 100). Jadi, kesimpulanya tujuan humas secara universal adalah untuk menciptakan, memelihara, meningkatkan dan memperbaiki citra organisasi dimata publik yang disesuaikan dengan kondisi-kondisi daripada publik yang bersangkutan. Untuk mencapai tujuan tersebut, diantaranya ialah mengembangkan good will dan memperoleh opini publik yang favorable atau menciptakan kerjasama berdasarkan hubungan yang harmonis dengan berbagai publik.

Definisi humas pemerintah dapat dikatakan hampir sama dengan definisi humas pada umumnya. Humas lembaga pemerintah, yakni “ merupakan suatu keharusan fungsional dalam rangka tugas penyebaran informasi kebijakan, program dan kegiatan-kegiatan lembaga pemerintah kepada masyarakat". (Rahmadi, 1999: 77) Humas dalam pemerintah merupakan kelanjutan dari proses penetapan kebijaksanaan, pemberian pelayanan kepada masyarakat dengan sikap yang disesuaikan dengan kepentingan orang atau golongan agar lembaga atau instansi dimana humas itu berada memperoleh kepercayaan dari publiknya, yaitu masyarakat dalam arti luas.

Pelayanan dan sikap yang baik sangat penting demi terciptanya pengertian dan penghargaan yang sebaik-baiknya. Humas pemerintah bertugas memberikan informasi dan penjelasan kepada khalayak atau publik mengenai kebijakan dan langkah-langkah atau tindakan yang diambil oleh pemerintah serta mengusahakan tunbuhnya hubungan yang harmonis antara lembaga atau instansi dengan publiknya dan memberikan pengertian kepada masyarakat tentang apa yang dikerjakan oleh instansi pemerintah dimana humas tersebut berada dan berfungsi.

\section{Proyek Infrastruktur}

Karakteristik Proyek Konstruksi pada umumnya, karakteristik proyek sangat mempengaruhi lingkungan sekitar. Terdapat beberapa faktor-faktor yang dapat mempengaruhi karakteristik proyek, antara lain : Keterbatasan lokasi dan lahan, resiko politik, resiko ekonomi, dampak pada publik, persetujuan teknis oleh otoritas, dan tersedia dana yang cukup.

Dalam meningkatkan perkembangan sosial dan kegiatan ekonomi wilayah, prasarana (infrastruktur) umum merupakan hal yang penting.Pembangunan tidak dapat berjalan dengan lancar jika prasarana tidak baik. Setiap aspek kehidupan sosial maupun ekonomi mempunyai prasarana sendiri, yang merupakan satuan terbesar dan alat utama dalam berbagai kegiatan. 
Oleh karena itu, dalam mengsukseskan pembangunan Volume Xx X Nomor xx Tahun 20xx kehidupan ekonomi harus memperhatikan infrastrukturnya. Berdasarkan pengalaman yang ada pembangunan sering terjadi tidak efisien dan efektif karena tidak sesuai dengan aspirasi daerah, tidak sesuai dengan potensi daerah dan permasalahan daerah, serta penyimpangan bersifat teknis maupun non-teknis yang tentu saja menimbulkan berbagai dampak sosial yang tidak sedikit. Proses pertumbuhan ekonomi wilayah dapat dipahami sebagai analogi dari proses pertumbuhan ekonomi nasional (McCann, 2001).

Perbedaan pokoknya terletak pada kenyataan bahwa pergerakan faktor produksi antar wilayah jauh lebih mudah terjadi dibandingkan dengan pergerakan faktor produksi antar negara. Akibat langsung dari fakta ini adalah peranan perdagangan antar wilayah menjadi penting dalam analisis pertumbuhanekonomi wilayah yang sudah tentu dengan dukungan infrastruktur yang memadai. Menyadari pentingnya infrastruktur dalam mendorong pertumbuhan ekonomi, para pakar infrastruktur sepakat bahwa dalam mendorong pembangunan infrastruktur, pemerintah sebagai pemain utama dalam sektor infrastruktur selayaknya menjaga kesinambungan investasi pembangunan infrastruktur dan memprioritaskan infrastruktur dalam rencana pembangunan nasional, sehingga infrastruktur dapat dibenahi baik secara kuantitas maupun kualitas.

Pembangunan infrastruktur juga sepatutnya melibatkan pihak swasta dan masyarakat demi tercapainya pembangunan berkesinambungan.Untuk itu perlu pendekatan lebih terpadu dalam pembangunan infrastruktur mulai dari perencanaan sampai pelayanannya kepada masyarakat, guna menjamin sinergi antar sektor, daerah maupun wilayah. Isu pembiayaan infrastruktur oleh pemerintah merupakan perbincangan yang sangat menarik dikalangan para pakar. Diakui oleh para pakar bahwa pemerintah memang menghadapi tantangan serius dalam pembiayaan infrastruktur, dimana keterbatasan dana menyebabkan tidak memungkinkan pemerintah mengandalkan metode pembiayaan konvensional untuk memenuhi kebutuhan infrastruktur yang terus meningkat. Bahkan untuk infrastruktur dimana kelayakan finansial tidak mungkin dicapai seperti di daerah terpencil dan pedesaan, dana pemerintah masih belum mencukupi mengingat biaya investasi yang cukup besar. (Hermanto Dardak http/www.ekorakyat.org).

Bagi daerah yang memiliki sumber dana memadai, permasalahan justru timbul pada bagaimana mengalokasikan dana dengan baik dan tepat agar sepenuhnya bermanfaat bagi kesejahteraan masyarakat. Sebaliknya, bagi daerah dengan sumber dana terbatas, 
permasalahannya menjadi lebih rumit. Selain harus mengoptimalkan sumber daya yang ada dalam kebijakan investasi, juga harus merumuskan kebijakan investasi yang mampu menstimulir atau merangsang pihak ketiga untuk dapat dan mau terlibat dalam kegiatan investasi infrastruktur ini. Apapun kondisi daerahnya, maka persoalan kebijakan investasi pengembangan infrastruktur saat ini menjadi persoalan yang krusial.

Hal ini di samping karena kebutuhan akan pengembangan infrastruktur terasa semakin besar, juga di masa depan banyak tantangan yang harus dihadapi dalam merumuskan kebijakan investasi bagi perkembangan teknologi, maupun perkembangan politik yang semakin dinamis. Dalam kerangka itulah workshop kebijakan investasi bagi infrastruktur ini diadakan, agar para pengambil keputusan di daerah, baik anggota legislatif maupun eksekutif daerah memiliki kapasitas yang lebih mumpuni, sehingga mampu bersama- sama dalam merumuskan kebijakan investasi pengembangan infrastruktur secara sinergis, strategis dan optimal, sesuai dengan perkembangan masyarakatnya, terutama dalam menghadapi tantangan-tantangan dimasa mendatang.

\section{CLOSING}

Kontraktor di Sumatera Barat dibawahi asosiasi Gabungan Perusahaan Kontruksi Nasional Indonesia (GAPEKSINDO). Dalam menjalin komunikasi dengan publiknya, kontraktor memiliki peran memberikan perencanaan, pengarahan, dan rekomendasinya dalam menentukan arah serta kebijaksanaan pelaksanaan proyek. Kontraktor juga berfungsi sebagai konsultan dalam suatu badan multi disiplin profesional, tangguh, dan independen yang bekerja untuk pemilik proyek dari awal perencanaan sampai pengoperasian proyek, mampu bekerjasama dengan arsitek guna mencapai hasil yang optimal dalam aspek waktu, biaya, serta kualitas seperti yang sudah ditetapkan sebelumnya. Peta masalah komunikasi kontraktor dan public terfokus pada pembangunan pasar, pasar dikelola oleh Dinas Pasar Kota Padang yang pengelolaan pembangunannya dianggarkan oleh Dinas Pembangunan Umum Provinsi Sumatera Barat. Permasalahan komunikasi muncul dari publik pembangunan infrastruktur yang sedang berjalan dapat dilihat di pasar raya, pasar banda buek, dan pasar lubuk buaya. Esensi komunikasi memegang peranan penting alam proyek infrastruktur kajian-kajian akademik yang dilakukan secara serius oleh pembelajar ilmu komunikasi terkait isu tersebut justru sangat minim. Untuk mengatasi kelangkaan tersebut, maka penelitian ini direncanakan akan mempelajari secara detil proses, karakteristik, power relations dan penyebab gagalnya proyek infrastruktur dari perspektif ilmu komunikasi, lebih khusus lagi Public Relations. 
Proses membina kebijaksanaan umum sebagai bentuk dinamika komunikasi Tahntraktor yang dijalin dengan publik apabila difokuskan lagi, sebenarnya dapat melahirkan konsep baru yakni Public Relations Infrastruktur yang bertugas menjamin pelaksanaan berbagai kebijaksanaan dan komunikasi mengenai kebijaksanaan kepada khalayak sehingga menghasilkan pertukaran gagasan formal secara dua arah antara sebuah organisasi dengan khalayaknya merupakan pencerminan dari fungsi hubungan masyarakat yang efektif dalam pelaksanaan pembangunan infrastruktur.

Dengan rekomendasi penelitian, dalam melaksanakan pembangunan, kontraktor harus meningkatkan perhatian dinamika komunikasi untuk mendukung keberhasilan proyek pembangunan infrastruktur. Kontraktor dan pihak-pihak terkait dalam pembangunan infrastruktur harus meningkatkan kepedulian terhadap esensi Komunikasi efektif dalam menumbuhkan kepercayaan kepada publik yang bersangkutan dengan pembangunan infrastruktur. Pemerintah terkait harus memberikan perhatian lebih dalam setiap pelaksanaan proyek pembangunan infrastruktur terkait, terutama Dinas Pekerjaan Umum dan Instansi Kedinasan terkait pembangunan. Bagi penelitian selanjutnya sebaiknya lebih mengkhususkan pada komunikasi budaya yang bertujuan memperkuat budaya lokal dalam menghadapi serangan budayaglobal.

\section{REFERENCES}

Chatra, E. (2017). „Dinamika Komunikasi Proyek Sukses dan Gagale. Harian Padang Ekspres. Teras Utama. 6 Desember.

Effendy, Onong Uchjana. 2000. Dinamika Komunikasi. Remaja Rosdakarya Bandung.

Ehling, W. P, (1984). „Application of decision theory in the construction of a theory of public relations management: I ${ }^{\text {ee }}$ dalam Jurnal Public Relations Research \& Education. 1(2). Hal. 25-38.

Ehling, W. P. (1985). „Application of decision theory in the construction of a theory of public relations management: II ${ }^{\mathrm{ee}}$ dalam Jurnal Public Relations Research \& Education. 2(1). Hal. 4-22.

Hutton, J. 1999, „The Definition, Dimensions,and Domain of Public Relations ${ }^{\mathrm{ee}}$, Public RelationsReview 25(2) (Summer), 199-214.

Ervianto, Wulfram I. 2005. Manajemen Proyek Konstruksi. Yogyakarta: Andi Offset.

Lauzen. M. M. (1986). Public Relations and Confict Within The Franchise System. Disertasi doktor. University of Maryland, College Park. 
Liu, B. F. dan Levenshus A. B. 2012. „Crisis Public Relations xor Tahun 20xx Communicators $^{e e}$ dalam Lee, M.,Neeley G,. Stewart K.. The Practice of Government Public Relations. Boca Raton - New York: CRC Press

Moore, Frazier. 2004. Humas Membangun Citra dengan Komunikasi. Bandung : PT. Remaja Rosdakarya.

Plowman, Kenneth D. 1998. „Power in Conflict for Public Relationse dalamJournal of Public Relations Research, 10 (4). Hal 237-261

Rahmadi, F. 1999. Public Relations dalam Teori dan Praktek. Jakarta:PT Gramedia Pustaka.

Ruslan, Rusadi. 2003. Manajemen Public Relations dan Media Komunikasi. Bandung : Raja Grafindo Persada.

Reklam AB, Jupiter. 2008. Crisis Communications Handbook. Huskvarna: Swedish Emergency Management Agency (SEMA)

Seeger, M. W., Sellnow, T. L., Ulmer R. R. 2001.,Public Relations and Crisis Communication Organizing and Chaos dalam Heath, R. L. (ed.),Handbook of Public Relations. California-London: Sage Publications, Inc. Hal. 155 - 165

Comfort, L. K. (2007). Crisis Management in Hindsight: Cognition, Communication, Coordination, and Control. Public Administration Review. December 2007 - Special Issue

Husain, Z. (2013). „Effective communication brings successful organizational change $\mathrm{e}^{\mathrm{e}}$. The Business \& Management Review, ol.3 Number-2, January

Jefkins, Frank. 1992. Public Relations (Edisi Keempat). Jakarta : Erlangga.

\section{Jurnal :}

Posumah, Ferdy. 2015. Pengaruh Pembangunan Infrastruktur terhadap Investasi di Kabupaten Minahasa Tenggara. Jurnal Berkala Ilmiah Efisiensi olume 15 No. 02 Tahun 2015

Chatra, Emeraldy. 2017. Tata Kelola Humas Pemerintah Daerah, Kajian di Tiga Instansi di Sumatera Barat. Jurnal Ranah Komunikasi ol.1 Edisi 12017

\section{Sumber Internet :}

https://www.cnnindonesia.com/ekonomi/20190107100702-532-358930/bank-duniasebut-proyek-infrastruktur-ri-berkualitas-rendah

https://padek.co/koran/padangekspres.co.id/cetak/berita/101803/Komunikasi_Sala $\underline{h, \text { Pembangunan Gagal }}$

https://lisalinda.staff.ugm.ac.id/2012/02/07/kegagalan-pembangunan-di-indonesia/ 